\title{
Pulmonary Embolism in a Patient with Primary Renal Synovial Sarcoma: The Important Differential Diagnosis of Tumor Embolism and Its Therapeutic Implications
}

\author{
Sabine Schmid ${ }^{a}$ Christian Öhlschlegel $^{b} \quad$ Wolfgang Nagel ${ }^{c}$ \\ Christoph Zeisel $^{c} \quad$ Joachim Müller ${ }^{d}$ Christian Rothermundt ${ }^{a}$ \\ Departments of ${ }^{a}$ Medical Oncology, ${ }^{b}$ Pathology, ${ }^{C}$ Vascular, Thoracic and Graft Surgery and \\ ${ }^{\mathrm{d}}$ Nuclear Medicine, Kantonsspital St. Gallen, St. Gallen, Switzerland
}

\section{Key Words}

Sarcoma · Primary renal synovial sarcoma - Tumor embolism · Thromboembolism .

Endobronchial ultrasound-guided transbronchial needle aspiration

\begin{abstract}
Pulmonary tumor embolism rarely occurs in epithelial-derived tumors, but it has been described in different tumor entities. Microscopic pulmonary tumor embolisms are often only discovered on autopsy. Pulmonary thromboembolism, on the other hand, is a frequent complication in cancer patients, and surgery in patients with a malignant tumor is an additional risk factor. The differential diagnosis between pulmonary thromboembolism and pulmonary tumor embolism can be challenging. In this case report, we describe the rare case of a patient with primary renal synovial sarcoma and the workup for a thrombus in the left pulmonary artery.
\end{abstract}

(c) 2013 S. Karger AG, Basel

\section{Case Report}

We report the case of a 52-year-old man with synovial sarcoma of the right kidney. Laparoscopic nephroureterectomy was performed in January 2012, under the suspicion of renal cell carcinoma (fig. 1). The postoperative course was complicated by pulmonary

Sabine Schmid, MD

Department of Medical Oncology/Hematology, Kantonsspital St. Gallen

Rorschacherstrasse 95

CH-9007 St. Gallen (Switzerland)

E-Mail sabine.schmid@kssg.ch 
embolism. The patient was put on anticoagulant therapy with low-molecular-weight heparin.

Surprisingly, the histologic findings were compatible with synovial sarcoma, verified by the detection of the typical $t(X, 18)$ translocation and the SYT/SSX fusion gene. The initial assessment confirmed stage III disease: pT2b (maximum tumor size $8.2 \mathrm{~cm}$ ), Nx M0 V1 (formation of a tumor thrombus in the right renal vein) G3.

According to a meta-analysis published in 1997, adjuvant chemotherapy can prolong progression-free survival, and there is a trend towards prolonged overall survival [1]. Further prospective studies have evaluated this question, and in high-grade soft tissue sarcomas adjuvant chemotherapy can be considered [2]. Adjuvant chemotherapy was discussed with our patient and, bearing in mind the high risk of recurrence in this case (tumor size, histologic grading and angioinvasion), 4 cycles of adjuvant chemotherapy with doxorubicin and ifosfamide were applied [3]. At the end of the treatment visit, a CT scan was performed and no tumor could be detected, but there was still evidence of a pulmonary embolus in the left inferior lobe. Subsequently, the patient was kept on anticoagulant therapy with low-molecular-weight heparin.

At the first follow-up visit 4 months after the completion of adjuvant chemotherapy, there was still no evidence of local tumor recurrence or metastases; however, in the area of the left inferior lobe pulmonary artery, a persisting soft tissue formation of unknown etiology could be documented. This entity was deemed most likely to be scar tissue after thromboembolism with pulmonary infarction or residual thrombus.

In the further follow-up period 3 months later, a CT scan showed progression of this soft tissue formation with partial occlusion of the left inferior lobe pulmonary artery (fig. 2); no uptake could be shown on PET/CT (fig. 3). Subsequently, a bronchoscopy with endobronchial ultrasound-guided transbronchial needle aspiration was performed for tissue sampling of the endoluminal thrombus. Histology revealed a spindle cell proliferation, which was compatible with metastasis of the known synovial sarcoma. At this time, no other sites of active disease could be detected on CT. Following data favoring metastasectomy in isolated pulmonary metastasis in selected patients [4], a lobectomy of the left lower lobe with subsequent resection of the lingula and bronchoplasty were performed (fig. 4). Histology confirmed a synovial sarcoma metastasis (fig. 5).

Written informed consent was obtained from the patient for publication of this case report and any accompanying images. A copy of the written consent form is available for review from the editor of this journal.

\section{Discussion}

Synovial sarcomas account for approximately 5-10\% of adult soft tissue sarcomas and most commonly arise in the proximity of large joints [5]. Primary renal sarcomas of any subgroup are a rare entity, but primary renal synovial sarcomas are extremely rare. To our knowledge, fewer than 70 cases have been mentioned in the literature since the first case was published in 2000 [6].

Malignant tumors in general carry an increased risk for thromboembolism; in addition, surgery is a known risk factor for pulmonary embolism or deep vein thrombosis. The risk varies and depends on cancer type and surgical intervention [7]. These facts explain why occurrence of pulmonary embolism shortly after surgery in a patient with synovial sarcoma did not raise any further suspicion. 
In order to further explore the hypothesis that the persistence of a clot 3 months after the occurrence of pulmonary embolism could explain the soft tissue formation in the area of the left inferior lobe pulmonary artery in our patient, we reviewed the literature concerning the rate of clot resolution under anticoagulant therapy following pulmonary embolism. Based on our findings, we decided to continue with therapeutic anticoagulation. In a systematic review published in 2006, it was concluded that complete resolution of the pulmonary embolus is not achieved in over $50 \%$ of patients 6 months after the diagnosis of pulmonary embolism [8]. The authors themselves pointed to the limitations of their final conclusion: in the studies considered for the review, the duration of anticoagulation therapy differed considerably in length and timing related to the follow-up scans [8].

A more recent study, published in January 2013, which compared CT and perfusion scintigraphy in documenting clot resolution after 3 weeks of anticoagulant treatment for pulmonary embolism, demonstrated that complete clot resolution could be measured on CT in $44 \%$ of patients (a slightly smaller proportion when measured with scintigraphy) [9]. Since no data were collected after 4 or 6 months, this cannot be directly compared to the results published in the aforementioned review.

In conclusion, a residual perfusion defect and residual thrombus 4 months after starting anticoagulant therapy does not seem to be a rare event, even though in $44 \%$ of patients with pulmonary embolism complete clot resolution can be achieved after 3 weeks of anticoagulant therapy.

Pulmonary tumor embolism is a rather rare incident that occurs in different tumor entities, mainly in epithelial-derived tumors. Microscopic pulmonary tumor embolisms are more frequent, difficult to diagnose and often only discovered postmortem; however, they can result in pulmonary hypertension or even cor pulmonale [10]. A number of case reports address tumor embolisms in sarcomas in general $[11,12]$, some of which occurred in clear association with surgery. Another rare differential diagnosis for pulmonary embolism is primary pulmonary artery sarcoma [13]. To our knowledge, only 1 case of tumor embolism in synovial sarcoma has been published so far [14] and no cases in primary renal synovial sarcoma, specifically.

Independent of the primary tumor, the main problem remains differentiating between pulmonary thromboembolism and pulmonary tumor embolism. Since the latter, all in all, is a very rare event compared to the high incidence of pulmonary embolism from blood clots, it most likely will rarely be a straightforward diagnosis.

FDG-PET/CT may be a useful diagnostic tool to differentiate between thromboembolism and tumor embolism, owing to its high sensitivity of over $90 \%$ in detecting sarcomas [15]. The sensitivity in synovial sarcomas in particular is about $80 \%$. However, as shown in our patient, a negative PET/CT scan does not exclude pulmonary tumor embolism, and a definitive diagnosis can only be made by means of pathologic tissue examination. The endobronchial ultrasound-guided transbronchial needle aspiration technique provides a new method to obtain tissue.

\section{Conclusion}

We would like to raise awareness to the possible differential diagnosis of pulmonary tumor embolism in cancer patients, especially when CT scans show atypical features or persisting perfusion defects despite appropriate anticoagulant therapy. 
Schmid et al.: Tumor Embolism in Primary Renal Sarcoma

\section{Disclosure Statement}

The authors declare that they have no competing interests.

\section{References}

-1 Sarcoma Meta-Analysis Collaboration: Adjuvant chemotherapy for localised resectable soft-tissue sarcoma of adults: meta-analysis of individual data. Lancet 1997;350:1647-1654.

-2 Italiano A, Delva F, Mathoulin-Pelissier S, Le Cesne A, Bonvalot S, Terrier P, Trassard M, Michels JJ, Blay JY, Coindre JM, Bui B: Effect of adjuvant chemotherapy on survival in FNCLCC grade 3 soft tissue sarcomas: a multivariate analysis of the French Sarcoma Group Database. Ann Oncol 2010;21:2436-2441.

-3 Kattan MW, Leung DH, Brennan MF: Postoperative nomogram for 12-year sarcoma-specific death. J Clin Oncol 2002;20:791-796.

-4 Blackmon SH, Shah N, Roth JA, Correa AM, Vaporciyan AA, Rice DC, Hofstetter W, Walsh GL, Benjamin R, Pollock R, Swisher SG, Mehran R: Resection of pulmonary and extrapulmonary sarcomatous metastases is associated with long-term survival. Ann Thorac Surg 2009;88:877-884.

5 Fisher C, De Bujin DR, Van Kessel AG: Synovial sarcoma; in Fletcher CD, Unni KK, Mertens F (eds): World Health Organization Classification of Tumors: Pathology and Genetics of Tumors of Soft Tissue and Bone. Lyon, IARC Press, 2002, pp 200-204.

6 Iacovelli R, Altavilla A, Ciardi A, Urbano F, Manai C, Gentile V, Cortesi E: Clinical and pathological features of primary renal synovial sarcoma: analysis of 64 cases from 11 years of medical literature. BJU Int 2012;110:1449-1454.

7 Heit JA, Silverstein MD, Mohr DN, Petterson TM, O’Fallon WM, Melton LJ 3rd: Risk factors for deep vein thrombosis and pulmonary embolism: a population-based case-control study. Arch Intern Med 2000;160:809-815.

-8 Nijkeuter M, Hovens MM, Davidson BL, Huisman MV: Resolution of thromboemboli in patients with acute pulmonary embolism: a systematic review. Chest 2006;129:192-197.

-9 van Es J, Douma RA, Kamphuisen PW, Gerdes VE, Verhamme P, Wells PS, Bounameaux H, Lensing AW, Büller HR: Clot resolution after 3 weeks of anticoagulant treatment of pulmonary embolism: comparison of computed tomography and perfusion scintigraphy. J Thromb Haemost 2013;11:679-685.

10 Roberts KE, Hamele-Bena D, Saqi A, Stein CA, Cole RP: Pulmonary tumor embolism: a review of the literature. Am J Med 2003;115:228-232.

11 Wong PS, Aye WM, Lee CN: Pulmonary tumor embolism secondary to osteosarcoma. Ann Thorac Surg 2004;77:341.

12 Arbeit JM, Flye MW, Mundinger GH Jr, Webber BL: Latent pulmonary embolus from a retroperitoneal sarcoma. Cancer 1980;46:1492-1498.

$13 \mathrm{Hu}$ XP, Xu JP, Liu NN: Primary pulmonary artery sarcoma: surgical management and differential diagnosis with pulmonary embolism and pulmonary valve stenosis. J Card Surg 2009;24:613-616.

14 Chamorro N, Blanco I, Sanchez M, Ramirez J, Barbera JA, Agusti C: The expanding horizons of endobronchial ultrasound: diagnosis of a tumor embolism. Chest 2012;142:1334-1336.

15 Charest M, Hickeson M, Lisbona R, Novales-Diaz JA, Derbekyan V, Turcotte RE: FDG-PET/CT imaging in primary osseous and soft tissue sarcomas: a retrospective review of 212 cases. Eur J Nucl Med Mol Imaging 2009;36:1944-1951. 


\section{Case Reports in Oncology}

Case Rep Oncol 2013;6:331-338

DOI: $10.1159 / 000353409$

Schmid et al.: Tumor Embolism in Primary Renal Sarcoma

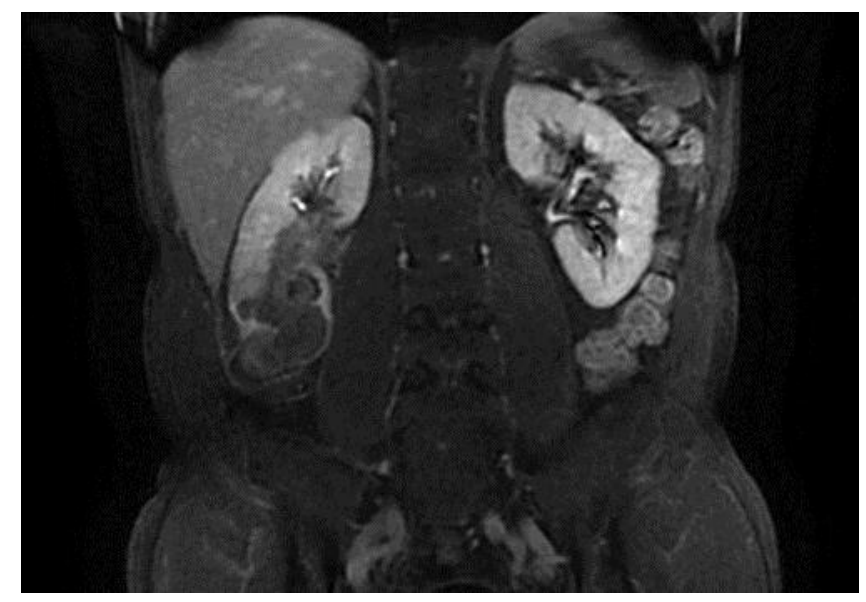

Fig. 1. Baseline magnetic resonance (MR) tomography with i.v. contrast (Dotarem) of the kidneys. An MR scan of the kidneys prior to laparoscopic nephroureterectomy exhibits a polylobulated, hypointense lesion extending from the renal pelvis to the lower pole of the right kidney. 


\section{Case Reports in Oncology}

\begin{tabular}{l|l}
\hline Case Rep Oncol 2013;6:331-338 \\
\hline DOI: $10.1159 / 000353409$ & $\begin{array}{l}\text { @ 2013 S. Karger AG, Basel } \\
\text { www.karger.com/cro }\end{array}$ \\
\hline
\end{tabular}

Schmid et al.: Tumor Embolism in Primary Renal Sarcoma

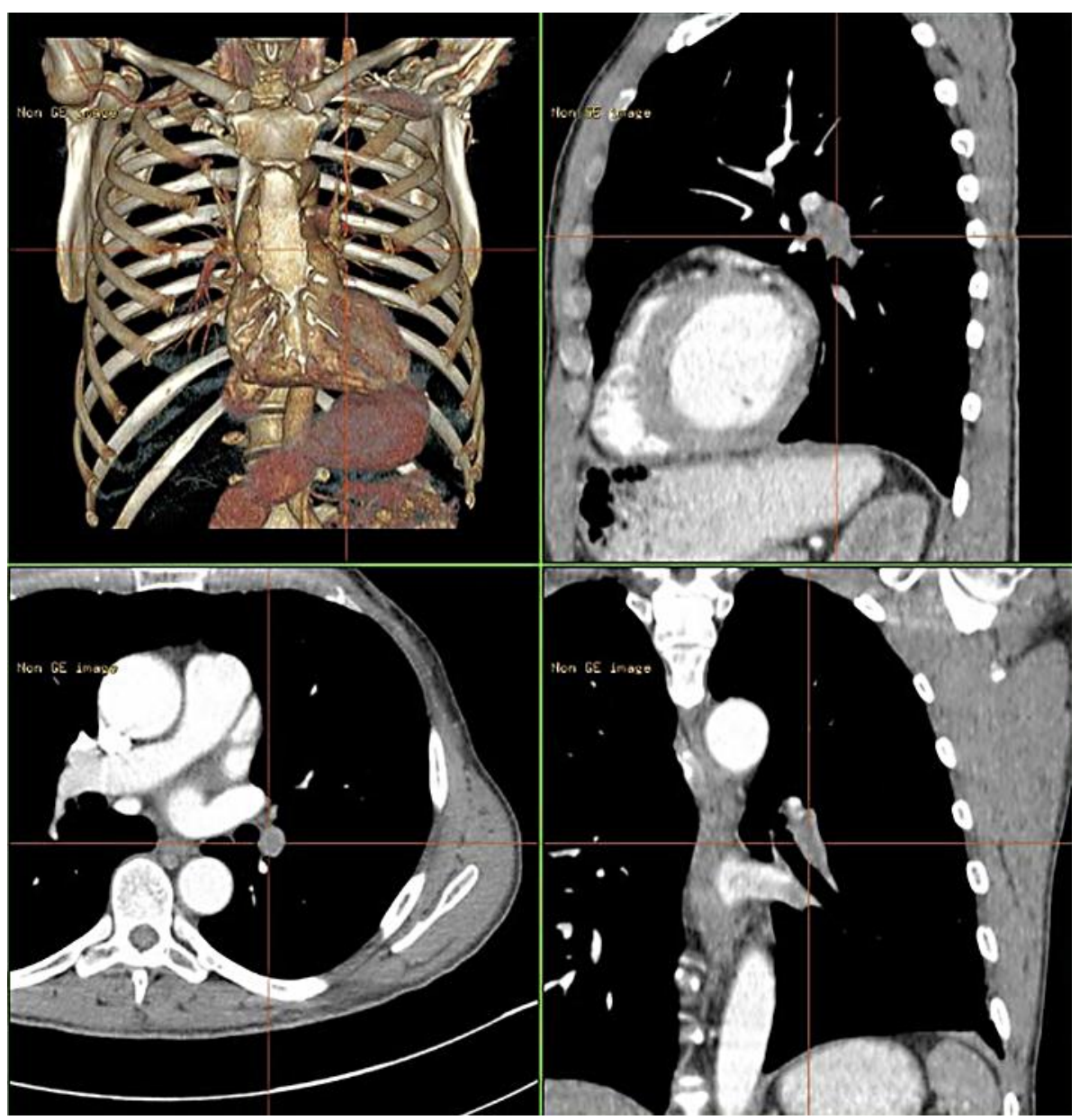

Fig. 2. CT scan 7 months after completion of adjuvant chemotherapy. Chest CT scan with i.v. contrast shows progression of a soft tissue formation in the left inferior lobe with partial occlusion of the left inferior lobe pulmonary artery. 


\section{Case Reports in Oncology}

\begin{tabular}{l|l}
\hline \multicolumn{2}{l}{ Case Rep Oncol 2013;6:331-338 } \\
\hline DOI: 10.1159/000353409 & $\begin{array}{l}\text { ○ 2013 S. Karger AG, Basel } \\
\text { www.karger.com/cro }\end{array}$ \\
\hline
\end{tabular}

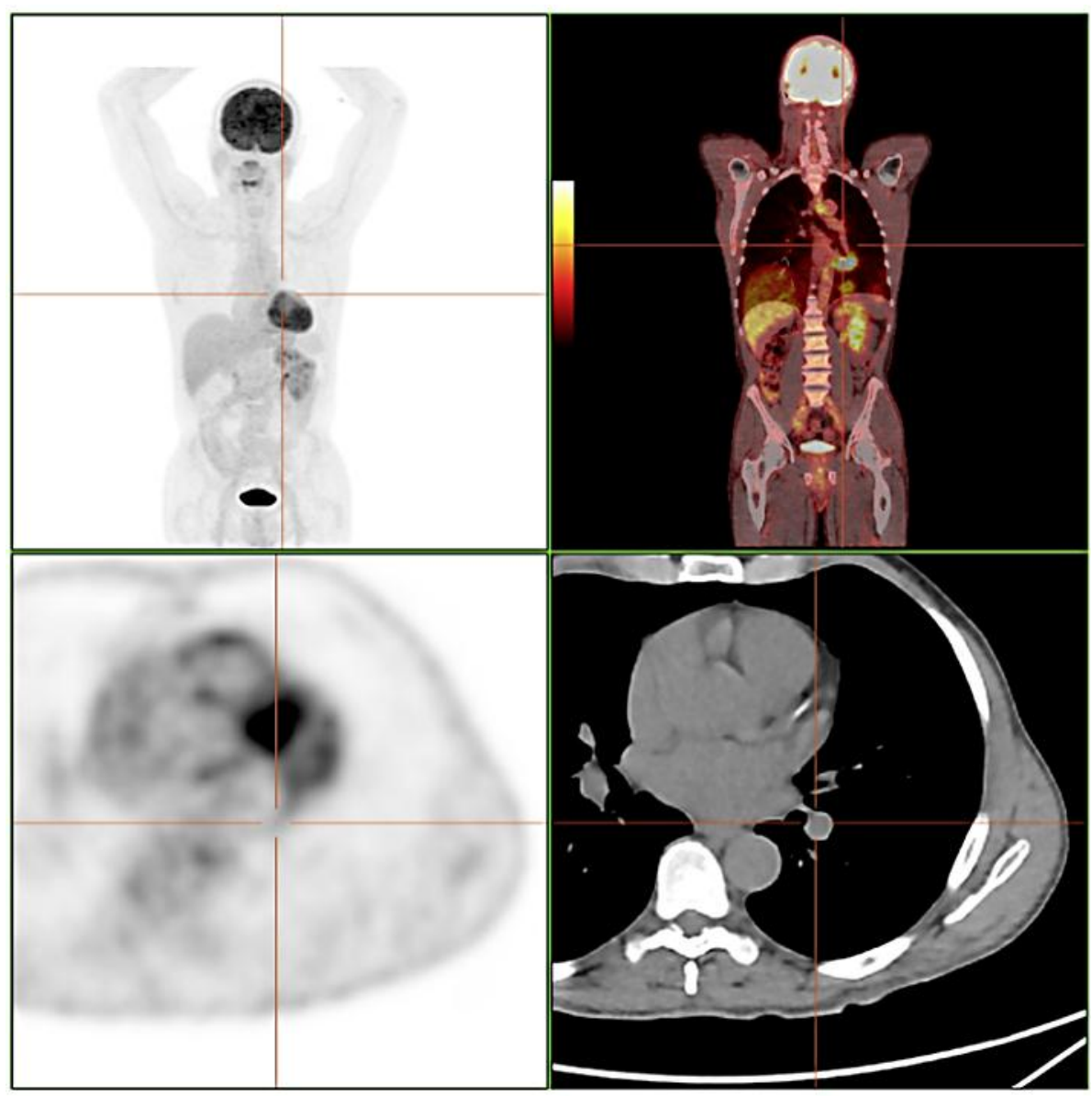

Fig. 3. FDG-PET/CT scan 7 months after completion of adjuvant chemotherapy. FDG-PET/CT scan performed at the same time as the CT scan (fig. 2) shows no FDG uptake of the described soft tissue formation. 


\section{Case Reports in Oncology}

\begin{tabular}{l|l}
\hline Case Rep Oncol 2013;6:331-338 \\
\hline DOI: $10.1159 / 000353409$ & $\begin{array}{l}\text { C 2013 S. Karger AG, Basel } \\
\text { www.karger.com/cro }\end{array}$ \\
\hline
\end{tabular}

Schmid et al.: Tumor Embolism in Primary Renal Sarcoma

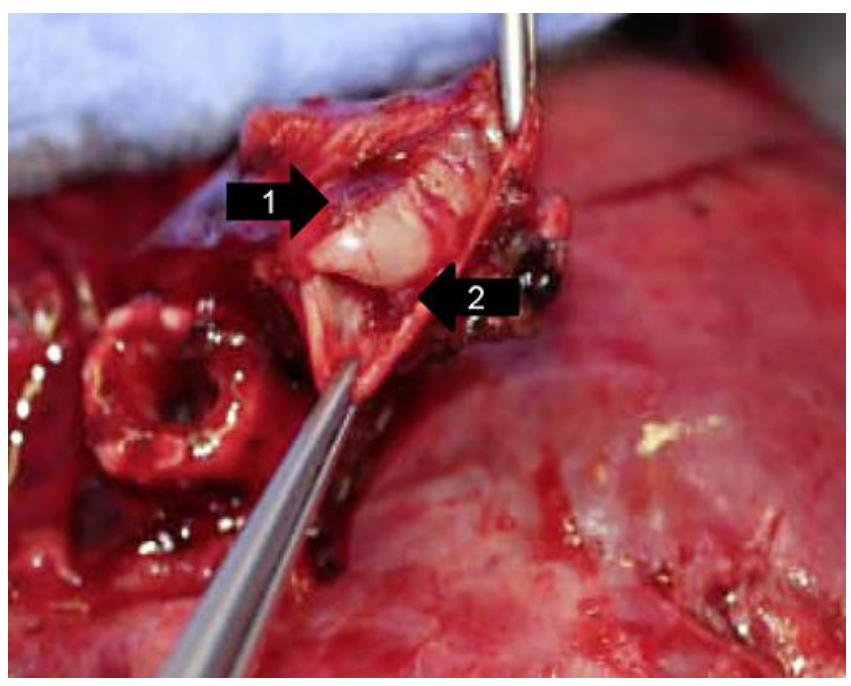

Fig. 4. Intraoperative situs during lobectomy of the left lower lobe with subsequent resection of the lingula and bronchoplasty. Arrow 1 shows the left inferior lobe pulmonary artery. Arrow 2 points to the intraluminal thrombus.

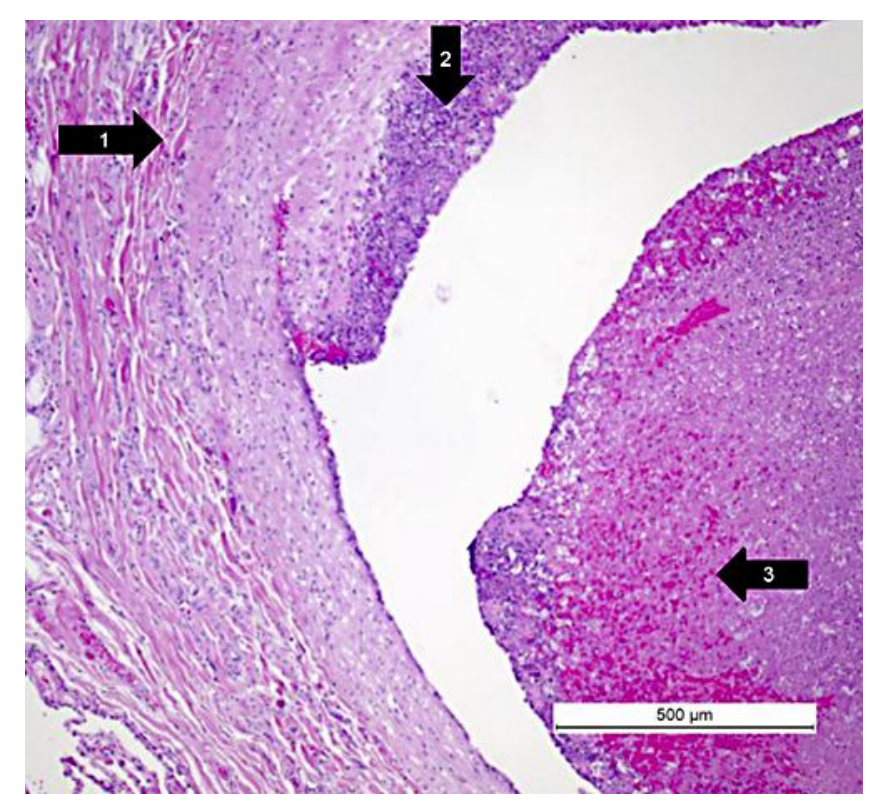

Fig. 5. Histology slide. Arrow 1 indicates the intima of the lingula artery of the left lung. Arrow 2 shows infiltration of the intima with synovial sarcoma cells. Arrow 3 demonstrates the intraluminal tumor thrombus of the synovial sarcoma. 